\title{
A obra de Leda Catunda: processo de criação e raciocínios femininos a partir de uma entrevista
}

Resumo

Este trabalho é resultante de uma entrevista feita com a artista plástica Leda Catunda, durante a qual foi dada ênfase para o feminino, o contexto e o processo de criação de suas obras. Dessa forma, faz uma leitura dos materiais e técnicas usados nas obras da artista, dentro de uma reflexão sobre a plasticidade das pinturas e dos suportes alternativos, assemblages personificadas matericamente em objetos e temáticas provenientes da cultura popular.

Palavras-chave:

Leda Catunda, processo criativo, arte contemporânea 


\title{
The creation process of Leda Catunda's work: reflections on an interview
}

JOEDY LUCIANA BARROS MARINS BAMONTE

\begin{abstract}
This study is resultant of the interview with the plastic artist Leda Catunda, when it emphasized for the feminine, the context and work's creative process. For this, handle a ready of the technique and materials used in the work of artist into the reflection of the plastic language that prize the pictures and alternatives supports, assemblages that materially personifies itself in objects and topics from the popular culture.
\end{abstract}




\section{Introdução}

O presente trabalho foi extraído de entrevista feita à artista plástica Leda Catunda, em seu próprio ateliê em 2002, para elaboração da tese de doutorado da autora: "Legado - Gestações da Arte Contemporânea: leituras de imagens e contextualizações do feminino na cultura e na criação plástica”. A obra da artista foi investigada, assim como a de Nazareth Pacheco, Edith Derdyk, Rosana Paulino e Leonilson, de forma que efetuasse uma investigação a respeito do fazer têxtil artesanal, em diálogo com a própria produção plástica da pesquisadora, a partir da obra "Legado", objeto de estudo da tese. Por isso, o universo feminino é apresentado de maneira enfática ao se abordar o processo de criação de Leda Catunda, algo já destacado durante a entrevista.

Desde o início de sua carreira, Leda Catunda é citada por criar um mundo próprio, originado na casa da mulher, composto por materiais baratos e presentes no interior dos lares. A própria artista brinca ao se referir aos próprios trabalhos como "cama, mesa e banho", já que nele estão presentes toalhas, cortinas, lençóis, colchões, tecidos baratos, produtos industrializados e utilizados no cotidiano. Como escreveria Carlos Scarinci, curador da Galeria Volpi, para o folder da exposição da artista em 1995 (CATUNDA, 1995), a artista é colocada entre a vanguarda e o popular, trabalhando com "a falta de 'classe', o anti-chic". Para ele, esta é uma atitude proposital, um gesto decorrente de um abandono, um descaso à arte tradicional.

Sua obra é associada à visualidade pop, à brasilidade e à feminilidade, brincando com os limites do bom gosto, com o popular ou o kitsch, dualidades que visitam o feio e o belo, o intelectual e o doméstico.

Sem medo de ousar ou inovar, investiga materiais, texturas que já vêm prontos das indústrias. Desta forma, quebra o hermético presente na arte, em procedimentos que 
constroem o processo criativo ao se apoderar de materiais populares, nem sempre nobres, como suportes para a obra artística ou seu objeto de estudo.

Quanto a essas características, pode-se encontrar nas obras da artista parentescos com obras de Hélio Oiticica e Lygia Clark, no Brasil, e com Tom Wesselman ou Claes Oldenburg, nos Estados Unidos, dentro de um diálogo com os anos sessenta.

\section{Início da carreira}

A carreira de Leda Catunda teve início, segundo a própria artista, de maneira precoce. Ainda estudante do Curso de Licenciatura em Artes Plásticas, na FAAP, começou a pintar sobre influência de Sérgio Romagnolo, seu colega no período. A pintura não era muito desenvolvida na faculdade, o que levava o artista a exercer a atividade de maneira caseira, segundo Leda. Junto a eles, trabalharam outros colegas como Ana Maria Tavares, Jac Leirner, Mônica Nador, entre outros, artistas que vieram a ter destaque no cenário artístico brasileiro a partir da década de 1980.

Dessa forma, mediante proposta feita por Romagnolo à diretora do MAC-USP, Aracy Amaral, a artista (junto ao grupo) participou da mostra "Pintura como Meio" em 1983, sendo somadas as presenças de Ana Maria Tavares, Ciro Cozzolino e Sérgio Niculitchef (os dois últimos residentes na Europa). Durante o período também conviveram José Leonilson, Edgard de Souza, Iran do Espírito Santo e Caetano de Almeida.

Em 1983, deu-se a mostra coletiva "Pintura como Meio", apresentada a então diretora do MAC-USP, Aracy Amaral, por Sérgio Romagnolo. A crítica de arte denominou as obras "uma jovem pintura em São Paulo" (AMARAL, 1983), as quais vieram a ser destacadas pelos críticos de arte pela ousadia e inovação de jovens ainda graduandos, um marco para a pintura paulista e brasileira.

\section{A Costura como "Raciocínio Feminino"}

Ao se efetuar a abordagem sobre a presença da costura em sua obra, a artista cita suas primeiras referências no período em que fez telas a óleo a partir de fotos da TV quando ainda estava na faculdade, em um processo semelhante ao que Sérgio Romagnolo também fazia. Durante a entrevista, Leda discorre sobre o assunto da seguinte forma: 
(...) Eu tirava de TV e revistas e aí eu usava essas imagens para fazer pintura. Mas comecei a achar que, quando apagava o slide, ficava só aquela pintura a óleo (...) a colocar uns tecidos por trás, colocar ou grudar na pintura e percebi as qualidades que eu podia aproveitar dos tecidos. Comecei a pensar em um trabalho em que as figuras já viessem direto no tecido. A mesma ideia de aproveitamento de uma figura pronta, mas não mais da TV ou da revista, não mais por foto, mas a figura que viesse impressa no tecido.

O procedimento relacionado à costura não foi programado. Surgiu de uma necessidade derivada do fazer artístico no qual se pretendia chegar a uma proporção mais adequada aos resultados esperados, ajustando-se o produto industrializado através da intervenção da costura:

E então, no primeiro trabalho que eu fiz, reparei que o tecido só tinha noventa centímetros, era uma flanela com uns gatinhos, uns bichinhos, assim (mostrando). Aí eu falei: ah, mas vai ficar estranho, pois eu quero um trabalho de dois metros. Vai ficar um "poste", não é? E eu peguei imediatamente e costurei as duas para ter então 1,80 x 2,oo e eu achei engraçado, porque todo mundo falou: "Mas você costurou?" "Você vai mostrar uma pintura costurada?" Nem me ocorreu que aquilo tivesse alguma estranheza porque na minha casa sempre teve máquina de costura.

Torna-se interessante a observação feita por Leda Catunda, ao mencionar a naturalidade daquele procedimento para ela pelo fato da costura lhe ser familiar, como algo sempre visto, já que acompanhava avó a costurar. Para ela, o ato de prender dois materiais está atrelado ao raciocínio de costurar, algo contrário ao que observou ao trabalhar com cinco artistas do sexo masculino na Casa 7 - Carlito Carvalhosa, Nuno Ramos, Fábio Migus, Paulo Monteiro e Rodrigo Andrade. Ao fazer essa observação, a artista enfatiza os procedimentos dos quais se utiliza para compor suas obras como atitudes mais femininas, um tipo de raciocínio que pensa em agulhas ou máquinas de costurar para unir materiais e prender partes de um trabalho.

Apesar de esclarecer, ao refletir sobre esses aspectos de seu trabalho, que a inserção da costura como algo proposital, inserido no contexto de sua criação e a possibilidade de conter um valor simbólico não constituem seu objeto de estudo, a artista, ao se deparar com a sua obra e exercitar a observa- 


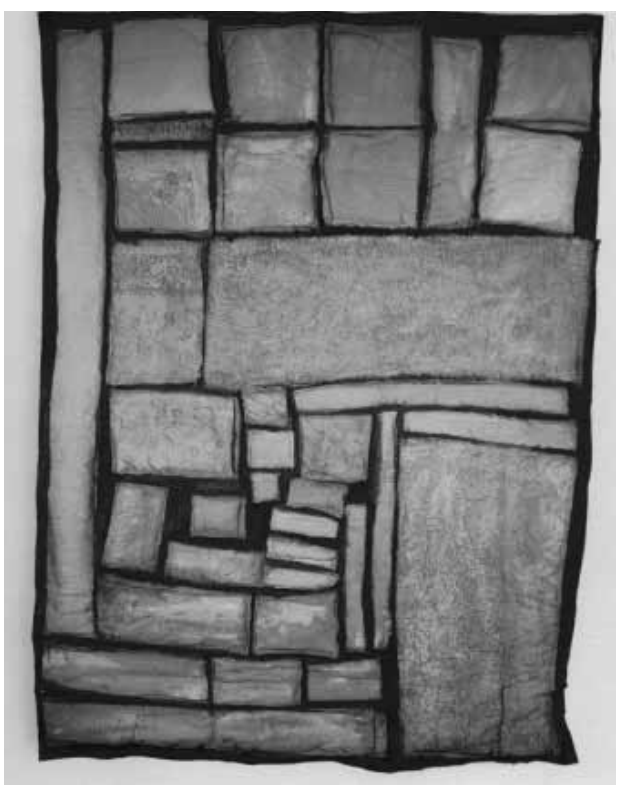

Figura 1

"Almofadas Azuis"

Leda Catunda, 1992,

acrílica s/ tecido e almo-

fada (CHIARELLI, 1998).

ção a partir do olhar do espectador, considera a existência de leituras que relacionem sua produção com o fazer artesanal feminino. Da mesma maneira que os trabalhos do Grupo Casa 7 remetem ao contexto masculino por estarem impregnados de reminiscências desse universo com "tudo pregado, serrado, soldado, parafusado", como diz a própria Leda, a costura e a presença do fazer artesanal têxtil estaria relacionado ao universo feminino em seu trabalho, apesar de não ser o seu foco, conforme consta no trecho da entrevista:

(...) eu não me concentro nisso, mas eu sei que isso, esse significado, está presente. Talvez haja uns dez anos, de uns dez anos para cá, eu passei a avaliar se eu queria que a costura aparecesse ou não, porque até certa altura, as costuras ficavam super evidentes, todos os encontros e pontos, às vezes linhas, que eu acabava deixando no trabalho. Depois eu encontrei um jeito de fazer uma costura que ficasse mais invisível e também pensei em outras formas de juntar materiais e fui dar nessa ideia dos ilhós com argola, que tem nesse trabalho atrás de você (aponta). Agora, o plástico está preso na lona com costura e as outras lonas vermelhas estão grudadas uma na outra, que é uma lona dupla. E aí tem os furinhos, os ilhós e argolas... eu acho que tem mesmo um significado, mas não é o assunto do meu trabalho. Talvez, seja muito mais a quali- 
dade dos tecidos, um pouco a escolha dos tecidos, as texturas, as cores, o aproveitamento de imagens e texturas e cores que já venham no próprio material.

O universo citado é composto por tecidos diversos, rendas, escolhidos pelo olhar que procura novos suportes ou o que está próximo dentro do processo de criação, texturas que componham um corpo a ser criado, com volumes e inserções de tinta que se abrem ao momento criativo. Segundo Sérgio Romagnolo, marido de Leda Catunda: "Ela trabalha como um tornado envolvendo tudo que vê em seu ateliê” (CATUNDA, 1995).

\section{Estrutura do Trabalho e Acabamento}

O trabalho de Leda Catunda chega, muitas vezes, a levantar questionamentos em relação ao conceito de gosto. Envolve o popular e o popularesco, a cultura de massa, inclusive ao trabalhar com os chamados objetos moles. A exposição de figuras, imagens da cultura de massa passa a ser investigada e transformada pela artista por meio de interferências da tinta em veladuras direcionando a leitura e reconstruindo signos. $\mathrm{O}$ kitsch aparece de maneira a explorar o que chama de "beleza cafona ou então uma coisa horrorosa", dependendo do leitor do trabalho. No entanto, o precário não é inserido, como fazia seu colega Leonilson, com quem partilhava visões muito próximas de criação, ao trabalhar a delicadeza em suas obras. O questionamento a impulsionar as criações de Catunda gira em torno do que lhe é suficiente no momento de execução da obra, dentro de um controle mínimo de acabamento plástico:

...faço um controle de um acabamento, mínimo... que é suficiente para mim. E isso varia totalmente para o meu espectador, desde pessoas que acham que é "superbem" acabado, quase "careta", o trabalho, e pessoas que acham que é totalmente alucinado: "como é que eu deixo aparecer o chassi?", quer dizer, a única medida que eu tenho é a minha própria. Eu não tenho uma preocupação com isto, mas a leitura das pessoas é a mais variada possível. Se pegar uns artistas jovens, eles falam "não, tem que ser muito mais 'estouradão' o trabalho!"

Seja usando agulha, linha, rebites, ilhós ou argolas, a costura é uma constante nas obras da artista paulistana. O artesanal está presente em todos os trabalhos, associados a tecidos como veludo, lona, recheios de espumas, edredons, almofadas. 


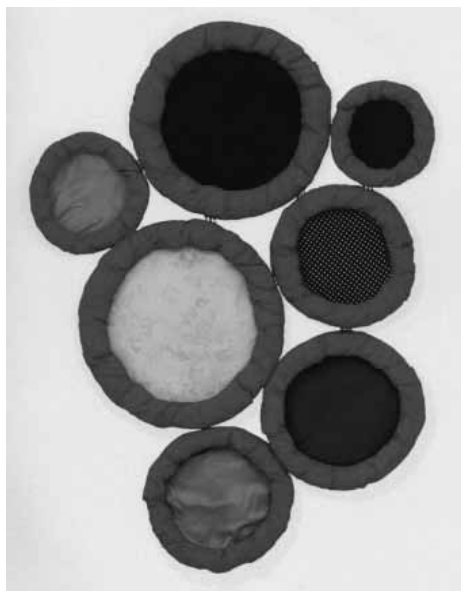

Figura 2

“Círculos”, Leda Catunda, 1992, acrílica s/ tela e tecido (CHIARELLI, 1998)

O material é manipulado de forma a proporcionar-lhes vida. Os volumes são reais, as sobreposições, a cor é usada para encorpar o tecido e estruturar o corpo da obra. Dessa forma, o uso de peças de enxoval é evidenciado na primeira parte do trabalho, segundo a própria artista:

Eu comecei a trabalhar os tecidos para pegar imagens, depois peguei imagens que estavam impressas em objetos moles, assim com cobertores, toalhas, e aí eu entrei nesse universo. Até trabalhei com colchões, edredons, almofadas e tal. Eu, às vezes, fazia uma brincadeira, que era "cama, mesa e banho".

\section{Diálogo com Outros Artistas}

Ao ser questionada quanto aos artistas que a influenciaram, Leda cita as obras de Regina Silveira, Júlio Plaza e Nelson Leirner, seus professores na faculdade. Posteriormente a essa fase, outros nomes foram somados, um grupo que a artista localiza como sua "família": Cildo Meireles, Waltércio Caldas, Carlos Fajardo, Luiz Paulo Baravelli, José Resende. As obras desses artistas teriam sido preponderantes na formação de sua poética visual.

Mesmo citando a Pop Art como influência sobre seu trabalho, ao enfatizar Andy Warhol, percebe-se nas criações de Leda Catunda referências a artistas próximos de contexto, brasileiros com os quais conviveu ou convive, seja através do contato pessoal ou da visualização in loco de obras no decorrer de sua vida, como as obras de professores ou contemporâneos como Carlos Fajardo ou Carmela Gross. 
Sobre artistas com os quais tem maior proximidade, destacou Ernesto Neto, salientando-se diálogos entre a sua produção final e a do artista. Para exemplificá-los, cita "Barriga”, uma obra sua feita em 1983, em acrílico sobre tela, na qual buscava o volume através do próprio material e da tinta. Em 2001, Ernesto, ao fazer um trabalho com duas "barrigas" voltadas para lados diferentes, o denominou "Leda Catunda", dentro de um tom bem humorado que também lhe é característico. Apesar desse diálogo, entre o movimento, o aspecto formal, Leda enfatiza a grande diferença entre o seu trabalho e o do artista pelo fato de Neto avançar no espaço e o fato de não conseguir pensar em identificação, afinidade no fazer entre os trabalhos mencionados. Tal afinidade visualiza na ligação com Leonilson:

Talvez aquele que eu tinha mais afinidade mesmo era o Leonilson, porque a gente era muito colega. Quando eu ia escolher um tecido, ele queria também, ou eu, que sempre via quais tecidos ele tinha comprado. A gente ia à loja juntos, às vezes ele me pedia pra costurar alguma coisa... aí eu sentia muito mais identificação. E mesmo o jeito que ele usava as cores do fundo, vários tipos de textura, assim... (...) Desde 83 ele fazia muita pintura sobre tela e, eu nunca sei, acho que na mesma hora que eu comecei a usar tecido ele começou a usar também e, às vezes, até ficava muito parecido com o meu... e aí ele me dava. (ri)

Acompanhou a evolução do trabalho de Leonilson, dizendo que faziam compartilhavam de visões muito próximas, refletidas em obras que dialogavam entre si. Esta proximidade iniciava-se nos momentos de criação, em identificações, familiaridades existentes no processo de elaboração das obras, semelhanças no fazer artístico, já que, segundo Leda, trabalhavam juntos no período.

\section{Relação da Artista com o Próprio Trabalho}

Em afinidade com a obra de Ernesto Neto, pode-se destacar também, na obra de Leda Catunda, o bom humor, a leveza e a maneira como apelida seus trabalhos. Durante a entrevista, período em que a artista estava desenvolvendo sua tese de doutorado sobre sua própria obra (defendida em 2002 sob o título "Poética da Maciez: Pinturas e Objetos"), mencionou o hábito de nominar seus trabalhos de forma que os identificas-

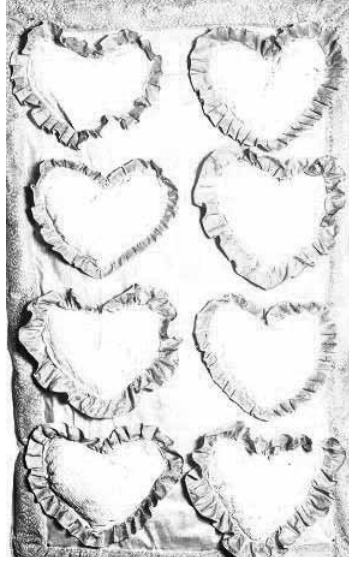

Figura 3

"Corações Brancos" Leda Catunda, 1992 acrílica s/ tecido e almofada (CHIARELLI, 1998) 
se imediatamente. Esta seria uma das questões levantadas por seu orientador, o artista plástico já falecido Dr. Júlio Plaza durante a produção da tese. Isto, somado ao costume do espectador apelidar as obras de "o redondinho", "o dos peixinhos"," a bolinha", o "quadradinho" justificava a oposição de Plaza, pelo fato do título conduzir a leitura, ao invés de remeter ao procedimento, à investigação, aspectos que dariam um caráter lúdico à obra, impedindo sua melhor compreensão.

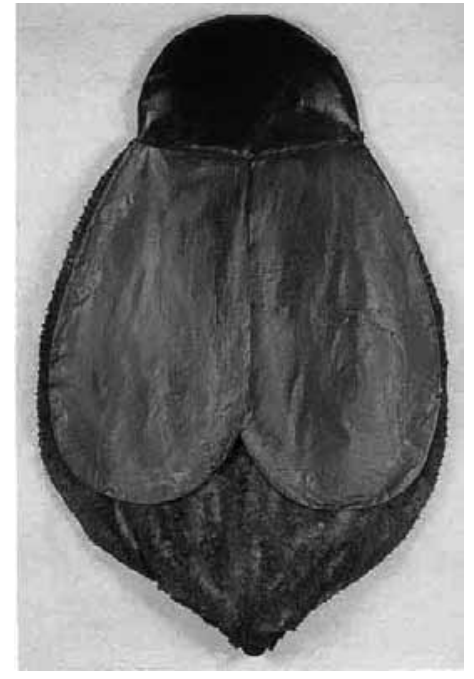

Figura 4

"Mosca", Leda Catunda, 1994, acrílica s/ tela, tecido e couro (LEDA, 2010)

Com isso, percebe-se uma tendência à espontaneidade na relação da artista com o fazer artístico, sem, no entanto, significar sinônimo de ingenuidade. $\mathrm{O}$ que poderia sugerir um esvaziamento, devido à projeção, é evitado à medida que se procura repensar a sua produção, não se esgotando em si mesma. Em sua própria fala:

Ah, um pouco, porque essa projeção, ela acaba sempre se tornando um certo desgaste. Qualquer um que fica exposto como eu fiquei ou vários outros artistas ficaram também no começo dos anos oitenta, começa a tomar certo cuidado com a qualidade do trabalho (...) porque o mercado também é muito apelativo. A cada dois, três anos, eu repenso o trabalho todo, pensando: "O que é que eu vou mostrar agora, para que eu não me repita, e tal?" Mas eu acho que o início dos anos oitenta marca um pouco uma virada assim, uma diferença. (...) desde 83 até 89 , eu fui num embalo, experimentando muitos materiais e tal, e aí eu acho que a partir de 92, eu comecei a 
me preocupar mais com as formas e com o que estava sendo representado. Eu substituí um pouco aquela figuração das imagens impressas nos objetos, por uma figuração sugerida, de formas orgânicas como a barriga, a boca, besouros, moscas - até que as moscas são bem figurativas... - pensando mais em volumes, sobreposições e procedimentos que me dariam uma visualidade menos narrativa do que eu vinha fazendo nos anos oitenta.

Eu acho que naquele momento e, talvez agora de novo, porque agora eu tenho introduzido imagens fotográficas e as leituras se modificaram muito, as pessoas começam a fazer associações entre imagens do real e as outras formas, cores e texturas.

\section{Contextualizações da Obra}

Ao mencionar o significado de sua obra e suas contextualizações na atualidade, a artista pontua a questão da visualidade do contemporâneo presente em sua produção. As obras seriam respostas ao bombardeio de informações presente no início do século XXI, incumbindo-se de refletí-lo e trazê-lo em forma de novos questionamentos. Para ela, isso se dá em seus trabalhos de uma maneira mais indireta e pessoal pelo fato de utilizar imagens do real. Daí, passa a trabalhar com seu imaginário e este, por conseguinte, a refletir o imaginário da classe média em fotos de viagem, de seu jardim, de si mesma.

Nesse universo, torna-se interessante mencionar o kitsch novamente. Leda levanta considerações a respeito dizendo que todos os seus trabalhos podem se prestar a isso, como os gostos podem ser divergentes e confluentes ao mesmo tempo, como variam de uma classe para outra, conforme menciona de maneira objetiva:

E acho muito curioso o gosto popular, como é uma coisa direta. Se "brilha" bastante, se é bem rosa, a pessoa gosta. Já, talvez, uma "madame" preferisse tons de branco a preto.

Essas observações são enfatizadas no período atual devido à comunicação exacerbada, causando visualidades que atravessam as classes, misturando-se e gerando outras visualidades. O trabalho feito pela artista dialoga com isso ao ser composto por materiais industrializados, que por sinal giram em torno do gosto. 
(...) na minha tese, tem um capítulo sobre o kitsch, até usando esse trabalho aqui com veludo vermelho (mostra), com esses laguinhos, usando essa ideia de paraíso, de águas.

Você já reparou que todos os lançamentos imobiliários agora são assim: "O mundo das águas azuis"... "tem cinco piscinas...” Quem que vai nadar tanto? Ninguém trabalha? ... São imaginários, e essas coisas acabam entrando no trabalho.

Figura 5

“Tamoios", Leda Catunda, 2004, acrílica s/ tecido (em pesquisa no período da entrevista) (LEDA, 2010)

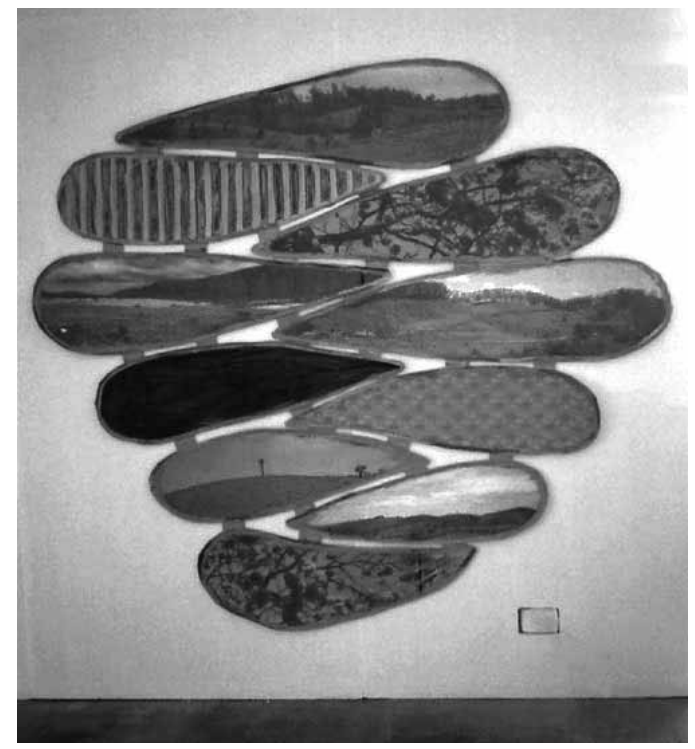

\section{Considerações sobre Influências da Infância}

(...) minha avó tinha uma confecção, onde eu ficava em Campinas. Bom, primeiro, se ela vinha para cá, sempre tinha essas máquinas - eu uso essa máquina Vigorelli de 1958 e nunca me modernizei e precisava me modernizar - e a minha avó tinha essas máquinas pretas, que a gente fica balançando o pedal. E aí, isso é realmente uma coisa que marcou a minha infância. A minha mãe ainda tem uma máquina dessas, mas ela fazia a confecção e como eu tinha que ficar com ela lá, ela me ensinava a pregar botão. Eu ia pregar botão em todas as peças. Sempre essa coisa do tecido... eu acho que tem um pouco esse lado autobiográfico (...)

Devido a essa influência, a artista confeccionava roupas para suas "Susies”, algo herdado da avó. 
É porque essas avós, são daquele tempo que a mulher não trabalhava, não trabalhava muito ou não estava combativa no mercado de trabalho, ou então, na verdade, elas faziam a maior grana e sustentavam, muitas vezes, a casa com a coisa tida como "de mulher" (...). Minha avó era quase uma operária, ela não parava de costurar. Ela tinha uma loja de roupa de crianças. Todas as roupas era ela quem fazia... então, ela fazia bem aquilo. Mas era um trabalho de mulher, mesmo. Permitido para mulher, não é?

\section{Processo de Criação (texto extraído, na íntegra, da entrevista)}

Vou fazer mais ou menos uma descrição do meu processo criativo.

Bom... eu tenho um assunto que quero trabalhar e faço investigações. Na verdade, eu faço muitos desenhos e colagens, uns papéis grudando várias coisas, meio como uma busca do assunto. Às vezes, em um trabalho mais concreto, eu passo para aquarelas que funcionam quase como um projeto dos trabalhos. Às vezes até, eu faço um grupo delas para ver que tipo de exposição eu vou fazer ou como eu juntaria os vários assuntos.

Também tem umas gravuras que me ajudam, porque quando você vai fazer gravura, vai pegar a pedra, é necessário fazer uma síntese da imagem. Então, isto é uma coisa paralela que me ajuda também. E, daqui para um trabalho grande, eu passo por esse tipo de desenho (mostra grandes moldes, como os de costura), que está ficando cada vez mais elaborado, porque antes eu só riscava direto no tecido ou fazia um desenho muito mais simples. Agora ele tem várias cores, está todo numerado, o que foi feito com o auxílio de uma assistente.

Agora está acontecendo uma coisa engraçada. Antes, esses desenhos (grandes moldes) que funcionam como um mapa para os trabalhos, eram jogados fora, mas agora eu faço uma coisa inversa... O curioso no processo de criação é que você vai e volta, vai e volta, não é? Tenho pensado em usar esses desenhos como obra, até para um tipo de trabalho que gere uma instalação. Na verdade, esses desenhos são a estrutura do trabalho.

Depois, os moldes adquirem uma visualidade toda impregnada de significados, acabando por perder um pouco do desenho. Talvez eles não sejam a parte mais importante, pois as questões acabam girando em torno do volume que o trabalho terá, de sua fisicalidade e não dos estudos iniciais. A obra final acaba sendo o assunto do trabalho. Entretanto, eu pensei de- 
pois, como num tipo de reviravolta, usar também esse desenho como o trabalho. Uma coisa que eu tenho pensado um pouco, mas ainda não realizei.

Os moldes de papel Kraft (como grandes partes de recortes como os usados por modelistas para confecção de roupas) normalmente funcionam como mapa para o trabalho, mas a investigação vai acontecendo em vários níveis. Depois eu faço outras coisas parecidas com maquetes, ensaios para os trabalhos, já como tipo de instrumento dos materiais, um pouco como isso aqui (mostra outro trabalho), que era para ser um trabalho, depois não era...

Tem umas coisas que eu vou fazendo dentro de uma pesquisa já com os materiais que serão utilizados nos trabalhos finais, em uma fase anterior a estes. Ou mesmo como esse aqui que você estava vendo (trabalho em veludo). É uma ideia dessas pinturas, já é uma tomada de posição. Eu faço uma grande seleção de todas as aquarelas, penso em que tipo de trabalho, em qual vai ser a cara de um grupo novo de trabalho. Por exemplo, agora eu devo preparar uma exposição para setembro, um grupo novo. Começo a fazer esses desenhinhos, aí eu penso: "Esse vai dar, esse não vai dar...” Tem uns que dão errado. Aí, pra fazer essas coisas ou essas (veludo), eu praticamente não penso nada. Ocorre na hora, e eu vou fazendo... eles são coisas coladas, depois eles vão ficando mais elaborados e acabam dando algumas sugestões fortes para mim, para pinturas.

Na exposição que fiz agora tinha um trabalho pequenininho feito com remendinhos desses filmes (tecidos impressos com imagens fotográficas). Esses são os filmes que eu uso fotografia (mostra o material). Aqui tem um pedacinho do mar, que tem um pouco da praia, aqui é uma árvore que tem aqui na frente da minha casa. Eu fotografei e imprimi no tecido. Também tinha um trabalho feito com retalhinhos que eu fui costurando, era totalmente feito em costura, possuía uma transparência. Eu nem sabia se dava para mostrar, entendeu? Porque isso é uma coisa que fica no ateliê. Assim, um raciocínio mais ou menos descomprometido... eu fui só juntando as várias faixas. Achei que essas listras tinham um assunto, um trabalho singular. Ele faz parte do raciocínio geral dos trabalhos que citei até agora e acredito que irá gerar um bem grande com essas imagens costuradas com uma linguagem, como se fosse um quebra-cabeças.

Então, eu acho que o processo passa por essas várias etapas, que é bem curioso, porque isso está na minha cabeça, está no ateliê, mas quando mostra lá na galeria... acho que isso ocorre com todo o artista. Assim como eu, todo espec- 
tador pode se deparar com uma obra como uma instalação da Regina Silveira e pensar: "Nossa, como ela chegou a isto?" Passa mais ou menos por esses caminhos.

\section{E a escolha dos materiais?}

Eu já trabalho faz tempo com vários tipos de materiais e tem alguns que eu gosto de repetir e que traz um significado curioso, assim como o veludo, que tem uma coisa meio nobre, meio brega, meio teatral, na verdade, não é? E aí eu mais ou menos repito o plástico, algumas rendas, eu gosto de variar texturas...

Então, muitas vezes, eu vou para as lojas, já para comprar uma coisa que eu já sei que tem. Ou, às vezes, eu até penso em um tecido de estofado e procuro nas lojas para ver se eu acho uma coisa semelhante como a que eu tinha imaginado e, às vezes, eu sou surpreendida por algum outro tipo, que eu nunca tinha pensado em usar...

\section{Considerações Finais}

A oportunidade de desenvolver uma pesquisa sobre um artista vivo constitui um privilégio. No entanto, a oportunidade de fazê-la através de uma entrevista, principalmente no interior do ambiente onde esse artista cria representa uma abertura ao seu universo e às obras ainda em processo, um aprendizado a partir das tintas ainda úmidas, dos esboços ainda sendo estruturados, dos moldes em construção. Ao adentrar nesse local, uma leitura da obra pelo entrevistador é feita ao contextualizar o mundo no qual também vive. Ele se localiza nos procedimentos ali presentes.

A visita ao ateliê de Leda Catunda e o texto produzido a partir desse contato permitiu não somente uma abertura à sua obra, como também à reflexão acadêmica a partir da perspectiva do artista com as mãos ainda produzindo sua obra, ao mesmo tempo em que concede a oportunidade da leitura mais complexa e abrangente, aproximando textos acadêmicos e plásticos, referências científicas de depoimentos, convergências enriquecedoras entre diversificados discursos.

\section{Referências Bibliográficas}

ARCHER, Michael. Arte contemporânea: uma história concisa. São Paulo: Martins Fontes, 2001.

BAMONTE, Joedy L. B. M. Leda Catunda: depoimento [ago. 
2002]. Entrevistador: Joedy L. B. M. Bamonte. São Paulo, 2002. 1 fita cassete (45 min). Entrevista concedida para a produção da tese.

. Leda Catunda: depoimento [ago. 2002]. Entrevistador: Joedy L. B. M. Bamonte. São Paulo, 2002. 1 videocassete (12 min). Entrevista concedida para a produção da tese.

. Legado - gestações da arte contemporânea: leituras de imagens e contextualizações do feminino na cultura e na criação plástica - São Paulo: Universidade de São Paulo, Escola de Comunicações e Artes, 2004. 307 p.

CANTON, Kátia. Novíssima arte brasileira: um guia de tendências. São Paulo: Iluminuras, 2001.

CATUNDA, Leda. Leda Catunda. Encarte da exposição. 1995. São Paulo: Galeria Volpi.

CHIARELLI, Tadeu. Arte internacional brasileira. São Paulo: Lemos, 1999. . Leda Catunda. São Paulo: Cosac \& Naify, 1998.

LEDA Catunda. Disponível em: < http://sergioeleda.sites. uol.com.br/>. Acesso em: 15 nov. 2010.

Recebido em: 01/o9/o9

Aceito em: 03/11/10 
JOEDY LUCIANA BARROS MARINS BAMONTE joedy@faac.unesp.br

Graduada em Educação Artística - Universidade Presbiteriana Mackenzie (1991); Mestre em Comunicação e Poéticas Visuais - UNESP (1998); Doutora em Ciências da Comunicação (Comunicação e Estética do Audiovisual/ Sistemas de Significação em Imagem e Som) - USP/ECA (2004). Artista Plástica e Profa. Assist. Dra. RDIDP - UNESP (DARG/ FAAC). Membro da ANPAP (CPA). 